\title{
HUBUNGAN PENGETAHUAN TENTANG MAKANAN BERSERAT DENGAN KEJADIAN KONSTIPASI PADA MAHASISWA FAKULTAS KEDOKTERAN UNIVERSITAS MALAHAYATI BANDAR LAMPUNG
}

\author{
Muhammad Amar Abyan ${ }^{1 *}$, Dwi Robbiardy Eksa ${ }^{2}$, Ika Artini ${ }^{3}$ \\ ${ }^{1}$ Mahasiswa FK Universitas Malahayati Bandar Lampung \\ ${ }^{2,3}$ Dosen FK Universitas Malahayati Bandar Lampung \\ Email Korespondensi: abyan234@gmail.com
}

\section{ABSTRACT: CORRELATION OF KNOWLEDGE ABOUT FIBER FOOD WITH CONSTIPATION IN MEDICINE FACULTY STUDENTS OF MALAHAYATI UNIVERSITY BANDAR LAMPUNG}

Background: Constipation can cause severe stress for sufferers because of the discomfort. Constipation is generally considered normal, but if left untreated, constipation can lead to more serious situations such as impaction (hard and dry stools) and obstruction. The average prevalence of constipation in adult patients worldwide is $16 \%$, while in pediatric patients it is $12 \%$. A systematic review reported that the prevalence of constipation increased at the age of $60-110$ years, ie $33.5 \%$, and was higher in the female sex.

Objective: To find out the relationship between knowledge about the importance of fibrous food and the incidence of constipation in students of the Faculty of Medicine, Malahayati University, Bandar Lampung in 2020.

Methods: This type of research is a quantitative, analytic survey design with a cross-sectional approach. The population of all 2016 FK students and a sample of 78 people using random sampling technique. Data collection using a questionnaire sheet. Data analysis using Chi-Square statistical test.

Results: The distribution of sex frequency is mostly female as many as 96 respondents (53.93\%). Constipation frequency distribution, with constipation category as many as 87 respondents $(48.9 \%)$. The distribution of the frequency of knowledge about the importance of fibrous food is mostly in the unfavorable category as many as 97 respondents (54.5\%).

Conclusion: There is a relationship between knowledge about the importance of fiber foods with the incidence of constipation. The results of the analysis obtained a value ( $p$-value $0.000<0.05)$. OR: 14,557.

Keywords: Knowledge, constipation

\section{INTISARI: HUBUNGAN PENGETAHUAN TENTANG MAKANAN BERSERAT DENGAN KEJADIAN KONSTIPASI PADA MAHASISWA FAKULTAS KEDOKTERAN UNIVERSITAS MALAHAYATI BANDAR LAMPUNG}

Latar Belakang : Konstipasi dapat menimbulkan stres berat bagi penderita akibat ketidaknyamanan. Pada umumnya konstipasi dianggap sebagai hal yang biasa namun jika tidak diatasi konstipasi dapat menimbulkan situasi yang lebih serius seperti impaksi (feses menjadi keras dan kering) dan obstruksi. Prevalensi ratarata keluhan konstipasi pada pasien dewasa di seluruh dunia adalah $16 \%$, sedangkan pada pasien anak adalah $12 \%$. Suatu systematic review melaporkan 
prevalensi konstipasi semakin meningkat pada usia 60-110 tahun yaitu 33.5\%, dan lebih tinggi pada jenis kelamin perempuan.

Tujuan: Diketahui hubungan antara pengetahuan tentang pentingnya makanan berserat dengan kejadian konstipasi Pada Mahasiswa Fakultas Kedokteran Universitas Malahayati Bandar Lampung Tahun 2020.

Metode: Jenis penelitian kuantitatif, rancangan survey analitik dengan pendekatan cross sectional. Populasi seluruh mahasiswa FK angkatan 2016 dan sampel 78 orang dengan teknik random Sampling. Pengambilan data menggunakan lembar kuesioner. Analisis data menggunakan uji statistik Chi Square.

Hasil: Distribusi frekuensi jenis kelamin, sebagian besar adalah jenis kelamin perempuan sebanyak 96 responden (53,93\%). Distribusi frekuensi kejadian konstipasi, dengan kategori mengalami konstipasi sebanyak 87 responden $(48,9 \%)$. Distribusi frekuensi pengetahuan tentang pentingnya makanan berserat, sebagian besar kategori kurang baik sebanyak 97 responden (54,5\%).

Kesimpulan : Ada hubungan antara pengetahuan tentang pentingnya makanan berserat dengan kejadian konstipasi. Hasil analisis diperoleh nilai ( $\mathrm{p}$-value $0,000<$ a 0,05$)$. OR: $14,557$.

Kata Kunci : Pengetahuan, konstipasi

\section{PENDAHULUAN}

Konstipasi biasa disebut sembelit atau susah buang air besar. Konstipasi banyak terjadi di masyarakat umum pada kelompok remaja dan dewasa awal, risiko terjadinya konstipasi lebih sering terjadi pada wanita dibandingkan dengan pria dengan angka perbandingan 4:1 (Susilawati, 2010). Konstipasi merupakan keluhan saluran cerna yang terbanyak pada usia lanjut. Terjadi peningkatan keluhan ini dengan bertambahnya usia; $30-40 \%$ orang berusia di atas 65 tahun mengeluh konstipasi. Di Inggris, 30\% orang berusia 60 tahun merupakan konsumen yang teratur menggunakan obat pencahar. Di Australia, sekitar $20 \%$ dari populasi berusia di atas 60 tahun mengeluh mengalami konstipasi dan lebih banyak terjadi pada perempuan dibandingkan pria (Sudoyo. dkk, 2014).

Konstipasi dapat menimbulkan stres berat bagi penderita akibat ketidaknyamanan. Pada umumnya konstipasi dianggap sebagai hal yang biasa namun jika tidak diatasi konstipasi dapat menimbulkan situasi yang lebih serius seperti impaksi (feses menjadi keras dan kering) dan obstruksi. Konstipasi kronis dapat mengakibatkan divertikulosis, kanker kolon, dan terjadinya hemoroid. Kanker kolon terjadi karena konsistensi tinja yang keras memperlambat pengeluaran tinja sehingga bakteri memiliki waktu yang cukup lama untuk memproduksi karsinogen dan karsinogen yang diproduksi menjadi lebih konsentrat (Sudoyo. dkk, 2014).

Serat pangan sangat diperlukan agar tidak mengalami sembelit sehingga buang air besar menjadi lancar. Serat pangan akan menghambat penyerapan gula dan cholesterol sehingga membantu meningkatkan kesehatan. Dianjurkan untuk mengonsumsi sumber karbohidrat yang masih banyak mengandung serat (whole grains) dan mengonsumsi sayuran yang banyak mengandung serat pangan. Berbagai kajian menunjukkan bahwa konsumsi 
sayuran dan buah-buahan yang cukup turut berperan dalam menjaga kenormalan tekanan darah, kadar gula dan kolesterol darah. mengendalikan tekanan darah. Konsumsi sayur dan buah yang cukup juga menurunkan risiko sulit buang air besar dan kegemukan. Hal ini menunjukkan bahwa konsumsi sayuran dan buah-buahan yang cukup turut berperan dalam pencegahan penyakit tidak menular kronik. Konsumsi sayuran dan buahbuahan yang cukup merupakan salah satu indikator sederhana gizi seimbang. (Kemenkes RI, 2014).

Masyarakat Indonesia masih sangat kekurangan mengonsumsi sayuran dan buah-buahan,63,3\% anak $>10$ tahun tidak mengonsumsi sayuran dan $62,1 \%$ tidak mengonsumsi buah-buahan. Padahal sayuran di Indonesia banyak sekali macam dan jumlahnya. Sayuran hijau maupun berwarna selain sebagai sumber vitamin, mineral juga sebagai sumber serat dan senyawa bioaktif yang tergolong sebagai antioksidan. Buah selain sebagai sumber vitamin, mineral, serat juga antioksidan terutama buah yang berwarna hitam, ungu, merah (Kemenkes RI, 2014).

Prevalensi rata-rata keluhan konstipasi pada pasien dewasa di seluruh dunia adalah $16 \%$, sedangkan pada pasien anak adalah $12 \%$. Suatu systematic review melaporkan prevalensi konstipasi semakin meningkat pada usia 60-110 tahun

\section{METODE PENELITIAN}

Jenis penelitian yang digunakan dalam penelitian ini adalah kuantitatif yaitu jenis penelitian yang mencoba mengetahui mengapa masalah kesehatan tersebut bisa terjadi kemudian melakukan analisis hubungannya (Riyanto, 2011).

Populasi dalam penelitian ini seluruh mahasiswa FK angkatan 2016 yaitu 33.5\%, dan lebih tinggi pada jenis kelamin perempuan. Prevalensi konstipasi pada masyarakat Asia seperti China, Korea, Hongkong dan India bervariasi antara $\quad 8.2 \% \quad$ sampai 16.8\%. Epidemiologi konstipasi di Indonesia sebesar 10,2\%. Suatu penelitian di Jakarta pada tahun 1998 - 2005, melaporkan bahwa dari 2.397 pemeriksaan kolonoskopi, sebanyak 9\% diantaranya dilakukan atas indikasi konstipasi, dimana penderita wanita lebih banyak dari pria.

Berdasarkan hasil pre survei yang peneliti lakukan pada tanggal 20 Februari Tahun 2020 dengan metode wawancara terhadap 10 mahasiswa Fakultas Kedokteran Universitas Malahayati Bandar Lampung, diketahui bahwa 6 orang (60\%) diantaranya mengatakan mengalami konstipasi serta nyeri pada saat buang air besar, ditemukan juga 7 dari 10 mahasiswa 70\% diantaranya tidak mengetahui secara pasti manfaat makanan berserat, jenis serta sumber makanan berserat. Berdasarkan fenomena tersebut peneliti tertarik untuk melakukan penelitian tentang pengetahuan makanan berserat dengan kejadian konstipasi pada mahasiswa Fakultas Kedokteran Universitas Malahayati Bandar Lampung.

di Universitas Malahayati Bandar Lampung Tahun 2019, sebanyak 320 orang.. Sampel sebanyak 178 responden yang diambil dengan Teknik random Sampling. Rancangan penelitian yang digunakan analitik dengan pendekatan cross sectional, yaitu penelitian yang mempelajari hubungan antara faktor resiko (independen) dan faktor efek (dependen) dimana pengukuran 
variabel bebas dan variabel terikat sekaligus pada waktu yang sama (Riyanto, 2011).
Pengambilan

data menggunakan lembar kuesioner. Teknik analisis data menggunakan uji statistik Chi Square

HASIL

Karakteristik Jenis kelamin

Tabel.1 Karakteristik Jenis Kelamin Pada Mahasiswa Fakultas Kedokteran di Universitas Malahayati Bandar Lampung Tahun 2020

\begin{tabular}{lcc}
\hline \multicolumn{1}{c}{ Jenis kelamin } & Frekuensi & Persentase $\%$ \\
\hline Laki-laki & 82 & 46,07 \\
Perempuan & 96 & 53,93 \\
\hline Jumlah & 178 & 100,00 \\
\hline
\end{tabular}

Berdasarkan Tabel 1 Lampung Tahun 2020, sebagian diketahui bahwa jenis kelamin pada besar adalah perempuan sebanyak mahasiswa Fakultas Kedokteran Universitas Malahayati Bandar

96 responden $(53,93 \%)$.

\section{Analisa Univariat}

a. Pengetahuan

Tabel.2 Distribusi Frekuensi Pengetahuan Tentang Pentingnya Makanan Berserat Pada Mahasiswa Fakultas Kedokteran di Universitas Malahayati Bandar Lampung Tahun 2020

\begin{tabular}{lcc}
\hline \multicolumn{1}{c}{ Pengetahuan } & Frekuensi & Persentase \% \\
\hline Kurang Baik & 97 & 54,5 \\
Baik & 81 & 45,5 \\
\hline Jumlah & 178 & 100,00 \\
\hline
\end{tabular}

Berdasarkan tabel 2 maka dapat diketahui bahwa pengetahuan tentang pentingnya makanan berserat pada mahasiswa Fakultas
Kedokteran Universitas Malahayati Bandar Lampung Tahun 2020, dengan kategori kurang baik sebanyak 97 responden $(54,5 \%)$.

b. Kejadian Konstipasi

Tabel. 3 Distribusi Frekuensi Kejadian Konstipasi Pada Mahasiswa Fakultas Kedokteran di Universitas Malahayati Bandar Lampung Tahun 2020

\begin{tabular}{lcc}
\hline \multicolumn{1}{c}{ Kejadian Konstipasi } & Frekuensi & Persentase \% \\
\hline Tidak mengalami Konstipasi & 91 & 51,1 \\
Mengalami Konstipasi & 87 & 48,9 \\
\hline Jumlah & $\mathbf{1 7 8}$ & $\mathbf{1 0 0 , 0 0}$ \\
\hline
\end{tabular}


Berdasarkan tabel 3

maka dapat diketahui bahwa

kejadian konstipasi pada

mahasiswa Fakultas Kedokteran
Universitas Malahayati Bandar Lampung Tahun 2020, dengan kategori mengalami konstipasi sebanyak 87 responden $(48,9 \%)$.

\section{Analisa Data Bivariat}

a. Uji normalitas

Tabel. 4 Uji Normalitas Pengetahuan

\begin{tabular}{lccc}
\hline \multicolumn{4}{c}{ Tests of Normality } \\
\hline & \multicolumn{3}{c}{ Kolmogorov-Smirnov ${ }^{\mathrm{a}}$} \\
\cline { 2 - 4 } & Statistic & $\mathrm{df}$ & Sig. \\
\hline Pengetahuan & 0.364 & 178 & 0.200 \\
\hline
\end{tabular}

$\begin{array}{lcr}\text { Uji } & \text { normalitas } & \text { dilakukan } \\ \text { untuk } & \text { mengetahui } & \text { apakah } \\ \text { sampel } & \text { yang } & \text { diteliti }\end{array}$ berdistribusi normal atau tidak. Pada penelitian ini sampel lebih dari 50 responden sehingga uji kenormalan yang digunakan adalah Uji Kolmogorov-Smirnov.
Kriteria uji normalitas adalah data berdistribusi normal jika taraf signifikan > a $(0,05)$. Dari hasil analisa uji normalitas pengetahuan diketahui taraf signifikan sebesar $0,200>(a$ $0,05)$.

\section{a. Hubungan Pengetahuan Dengan Kejadian Konstipasi}

Tabel. 5 Analisa Hubungan Pengetahuan Tentang Pentingnya Makanan Berserat Dengan Kejadian Konstipasi Pada Mahasiswa Fakultas Kedokteran di Universitas Malahayati Bandar Lampung Tahun 2020

\begin{tabular}{|c|c|c|c|c|c|c|c|c|}
\hline \multirow{3}{*}{ Pengetahuan } & \multicolumn{4}{|c|}{ Kejadian Konstipasi } & & & \multirow{3}{*}{$\begin{array}{c}\mathrm{p}- \\
\text { value }\end{array}$} & \multirow{3}{*}{$\begin{array}{c}\text { OR } \\
(95 \% \mathrm{Cl})\end{array}$} \\
\hline & \multicolumn{2}{|c|}{$\begin{array}{l}\text { Mengalami } \\
\text { Konstipasi }\end{array}$} & \multicolumn{2}{|c|}{$\begin{array}{c}\text { Tidak } \\
\text { mengalami } \\
\text { Konstipasi }\end{array}$} & \multicolumn{2}{|c|}{ Total } & & \\
\hline & $n$ & $\%$ & $\mathrm{n}$ & $\%$ & $\mathrm{n}$ & $\%$ & & \\
\hline Kurang Baik & 73 & 75,3 & 24 & 24,7 & 97 & 100 & & \\
\hline Baik & 14 & 17,3 & 67 & 82,7 & 81 & 100 & 0,000 & $(6,960$ - \\
\hline Total & 87 & 48,9 & 91 & 51,1 & 178 & 100 & & $30,444)$ \\
\hline
\end{tabular}

Berdasarkan tabel 5 diketahui bahwa dari 97 responden dengan kategori pengetahuan kurang baik dan mengalami konstipasi sebanyak 73 responden $(75,3 \%)$ dan tidak mengalami konstipasi sebanyak 24 responden (24,7\%), sedangkan dari 81 responden dengan kategori pengetahuan kategori baik dan mengalami konstipasi sebanyak 14 responden $(17,3 \%)$, dan tidak mengalami konstipasi terdapat 67 responden (82,7\%). Hasil uji statistik $\mathrm{p}$ - value $=0,000$ lebih kecil dari nilai alpha $(\alpha=0,05)$, sehingga terdapat hubungan yang bermakna antara pengetahuan 
dengan kejadian konstipasi pada mahasiswa Fakultas Kedokteran Universitas Malahayati Bandar Lampung Tahun 2020. Hasil analisis diperoleh nilai OR: 14,557. Artinya responden dengan pengetahuan

\section{PEMBAHASAN}

\section{Univariat}

\section{a. Pengetahuan}

Berdasarkan hasil dari pengolahan data maka dapat diketahui bahwa pengetahuan tentang pentingnya makanan berserat pada mahasiswa Fakultas Kedokteran Universitas Malahayati Bandar Lampung Tahun 2020, dengan kategori kurang baik sebanyak 97 responden (54,5\%). Berdasarkan hasil dari pengolahan data maka dapat diketahui bahwa kejadian konstipasi pada mahasiswa Fakultas Kedokteran Universitas Malahayati Bandar Lampung Tahun 2020, dengan kategori tidak mengalami konstipasi sebanyak 91 responden $(51,1 \%)$.

Hal ini dikarenakan ada faktor lain selain pengetahun seperti pola makan yang baik yang dikonsumsi pada mahasiswa. Hal ini sejalan dengan penelitian yang dilakukan Wulandari (2016) tentang hubungan asupan serat dengan kejadian konstipasi pada pekerja di PT. Tiga Serangkai Surakarta. Hasil penelitian diketahui bahwa pekerja yang tidak mengalami konstipasi sebanyak $65,2 \%$ dan pekerja yang mengalami konstipasi sebanyak $34,8 \%$.

Berdasarkan hal tersebut peneliti berpendapat bahwa pengetahuan mahasiswa tentang pentingnya makanan berserat tersebut dikarenakan kurangnya pemahaman mereka terhadap informasi mengenai makanan berserat yang berdampak pada pengetahuan ibu mahasiswa dalam perilaku kesehatan. Untuk itu yang kurang baik berisiko sebesar 14,557 kali anak mengalami konstipasi dibandingkan anak dengan pengetahuan baik.

disarankan mahasiswa agar mengkonsumsi makanan beraneka ragam serta makanan yang kaya serat seperti sayuran dan buahbuahan.

\section{b. Hubungan antara pengetahuan dengan kejadian konstipasi}

Hasil uji statistik p-value $=$ 0,000 lebih kecil dari nilai alpha ( $\alpha=0,05)$, sehingga terdapat hubungan yang bermakna antara pengetahuan dengan kejadian konstipasi pada mahasiswa Fakultas Kedokteran Universitas Malahayati Bandar Lampung Tahun 2020. Hasil analisis diperoleh nilai OR: 14,557. Artinya responden dengan pengetahuan yang kurang baik berisiko sebesar 14,557 kali anak mengalami konstipasi dibandingkan anak dengan pengetahuan baik.

Hasil ini juga sejalan dengan penelitian yang dilakukan Wulandari (2016) tentang hubungan asupan serat dengan kejadian konstipasi pada pekerja di PT. Tiga Serangkai Surakarta. Berdasarkan hasil analisis hubungan dengan uji Chi Square di dapatkan $\mathrm{p}=0,026$ terdapat hubungan antara asupan serat dengan kejadian konstipasi.

Hasil penelitian ini bertolak belakang dengan hasil penelitian Thea., Sudiarti., Djokosujono (2020). Mengenai hubungan antara jenis kelamin, asupan serat, cairan, konsumsi minuman probiotik, aktivitas fisik, status gizi, stres, dan pengetahuan gizi terhadap kejadian konstipasi fungsional, serta faktor dominan 
terhadap kejadian konstipasi fungsional pada remaja di Jakarta. Diketahui bahwa tidak ada hubungan antara pengetahuan gizi terhadap kejadian konstipasi fungsional, diperoleh nilai p-value. 0,0710 .

Hasil tabulasi silang diketahui bahwa dari 97 responden dengan kategori pengetahuan kurang baik tetapi tidak mengalami konstipasi sebanyak 24 responden (24,7\%), Hal ini dikarenakan faktor konsumsi makanan berserat yang dikonsumsi responden tersebut seperti sayur-sayuran dan buahbuahan. makanan memiliki kemampuan mengikat air didalam kolon yang membuat volume feses menjadi lebih besar dan akan merangsang saraf pada rektum yang kemudian menimbulkan keinginan untuk defekasi sehingga feses lebih mudah dieliminir. Sedangkan dari 81 responden dengan kategori pengetahuan kategori baik dan mengalami konstipasi sebanyak 14 responden $(17,3 \%)$, hal ini dikarenakan pola hidup pada responden tersebut seperti kurang minum, kebiasaan buang air besar yang tidak teratur, dan kurang olah raga yang menyebabkan responden tersebut mengalami konstipasi.

\begin{tabular}{lrr}
\multicolumn{2}{c}{ Berdasarkan hal } & tersebut \\
peneliti & berpendapat & bahwa \\
beberapa & penyakit & saluran \\
pencernaan & makanan & seperti
\end{tabular} konstipasi berkaitan erat dengan asupan serat pangan. Serat pangan berguna dan dipercaya dapat mencegah konstipasi yang erat kaitannya dengan sifat laksative, yaitu memudahkan buang air besar. Asupan serat makanan yang cukup sesuai dengan asupan serat makanan dengan standar kecukupan dapat mengurangi resiko konstipasi. Perubahan pola makan bagi siswa dan siswinya seperti lebih sering mengkonsumsi makanan yang serba instan dan cepat tanpa memperhatikan kandungan gizi yang terdapat pada makanan. Hal tersebut secara tidak langsung berhubungan dengan kurangnya konsumsi asupan serat makanan dan cairan dengan berbagai masalah kesehatan.

\section{KESIMPULAN}

1. Distribusi frekuensi jenis kelamin pada mahasiswa Fakultas Kedokteran di Universitas Malahayati Bandar Lampung Tahun 2020, sebagian besar adalah jenis kelamin perempuan sebanyak 96 responden $(53,93 \%)$.

2. Distribusi frekuensi kejadian konstipasi pada mahasiswa Fakultas Kedokteran di Universitas Malahayati Bandar Lampung Tahun 2020, dengan kategori mengalami konstipasi sebanyak 87 responden $(48,9 \%)$.

3. Distribusi frekuensi pengetahuan tentang pentingnya makanan berserat pada mahasiswa Fakultas Kedokteran di Universitas Malahayati Bandar Lampung Tahun 2020, sebagian besar kategori kurang baik sebanyak 97 responden (54,5\%).

4. Ada hubungan antara pengetahuan tentang pentingnya makanan berserat dengan kejadian konstipasi pada mahasiswa Fakultas Kedokteran di Universitas Malahayati Bandar Lampung Tahun 2020. Hasil analisis diperoleh nilai ( $\mathrm{p}$-value $0,000<$ a 0,05). OR: 14,557 .

\section{SARAN}

a. Universitas Malahayati

Diharapkan agar pengelola asrama dapat berperan aktif dalam pemantauan makan mahasiswa dan diharapkan dapat melakukan penyuluhan mengenai diet serat 
dan perlunya konsumsi air terhadap kesehatan saluran cerna dan dapat bekerja sama dengan instansi terkait seperti Puskesmas maupun tenaga pendidik kesehatan yang ada di Universitas Malahati untuk memberikan penyuluhan mengenai diet serat dan air secara teratur atau berkala.

\section{b. Mahasiswa}

Diharapkan mahasiswa perlu memperhatikan konsumsi makanannya, yaitu lebih meningkatkan makanan yang mengandung serat makanan seperti buah sebanyak 2-3 porsi dan sayur sebanyak 3-4 porsi setiap harinya dan konsumsi air sesuai kebutuhan yang dianjurkan sehingga meminimalisir konstipasi fungsional

c. Peneliti Lain

Diharapkan dengan penelitian ini dapat menjadi tambahan informasi dan pengembangan penelitian berikutnya dan untuk melanjutkan penelitian serta meneliti variabel lain yang berbeda seperti meneliti faktor-faktor yang berhubungan dengan kejadian konstipasi pada mahasiswa seperti diet rendah serat, kebiasaan defakasi, kebiasaan aktivitas, asupan cairan dan penyakit miogenik.

\section{DAFTAR PUSTAKA}

Akmal, Mutaroh, dkk. (2010). Ensiklopedi Kesehatan Untuk Umum. Jogjakarta: Ar-Ruzz Media.

Almatsier, S. (2013). Prinsip Dasar Ilmu Gizi. Jakarta: Gramedia Pustaka Utama.

Budiman., Agus Riyanto. (2013). Kapita Selekta Kuesioner. Jakarta: Salemba Medika.

Dahlan, M.S. (2011). Statistik Untuk Kedokteran Dan Kesehatan. Salemba medika: Jakarta.
Djojoningrat Dharmika. (2009). Pendekan Klinis Penyakit Gastroenterologi. In: Sudoyo W. Aru, ed. Buku Ajar Ilmu Penyakit Dalam. Jakarta: Internal Publishing.

Endyarni \& Syarif. (2014). Konstipasi Fungsional . Sari Pediatri, Vol. 6, No. 2.

Hastono, Sutanto Priyo. (2017). Analisis Data Pada Bidang Kesehatan. Depok: Raja Grafindo Persada.

Herawati, F. (2012). Panduan Terapi Aman Selama Kehamilan. Surabaya: PT. ISFI.

Kemenkes RI. (2017). Profil Kesehatan Indonesia. Katalog Dalam Terbitan. Jakarta: Kementerian Kesehatan RI.

Kemenkes RI. (2014). Pedoman Gizi Seimbang. Katalog Dalam Terbitan. Jendral Bina gizi dan KIA. Jakarta: Kementerian Kesehatan RI.

Notoatmodjo, S. (2018). Metodologi Penelitian Kesehatan (Cetakan VI). Jakarta: Penerbit PT. Rineka Cipta.

Notoatmodjo, S. (2014). Perilaku Kesehatan. Jakarta: Penerbit PT. Rineka Cipta.

Notoatmodjo, S. (2014). Promosi Kesehatan. Jakarta: Penerbit PT. Rineka Cipta.

Pradani., Rahfiludin \& Suyatno. (2015). Hubungan asupan serat, lemak, dan posisi buang air besar dengan kejadian konstipasi di Panti jompo Pucung Gading Semarang. Jurnal Kesehatan Masyarakat (e-Journal) Volume 3, Nomor 3, April 2015 (ISSN: 2356-3346) http://ejournals1.undip.ac.id/index.php/jk $\underline{m}$

Riyanto. A. (2011). Aplikasi Metodelogi Penelitian Kesehatan. Yogyakarta: Nuha Medika. 
Saryono \& Anggraeni. (2013). Metode Penelitian Kualitatif dan Kuantitatif Dalam Bidang Kesehatan. Yogyakarta: Nuha medika.

Saputra., Marlenywati., Saleh. (2016). Hubungan antara asupan serat dan cairan (Air Putih) Dengan Kejadian Konstipasi Pada Lansia di Wilayah Kerja Puskesmas Saigon Kecamatan Pontianak Timur. Fakultas IImu Kesehatan. Universitas Muhammadiyah Pontianak.

Sudoyo dkk. (2014). Buku Ajar Ilmu Penyakit Dalam. Jilid III Edisi VI. Jakarta: Interna Publishing.

Suhardjo. (2015). Perencanaan Pangan dan Gizi. Jakarta: Bumi Aksara.

Thea., Sudiarti., Djokosujono (2020). Hubungan antara jenis kelamin, asupan serat, cairan, konsumsi minuman probiotik, aktivitas fisik, status gizi, stres, dan pengetahuan gizi terhadap kejadian konstipasi fungsional pada remaja di Jakarta. Jurnal Gizi Klinik Indonesia. Vol. 16 No. 4, April 2020 (129-136). ISSN 1693-900X (Print), ISSN 25024140 (Online). Tersedia online di

https://jurnal.ugm.ac.id/jgk i DOI:

https: / / doi.org/10.22146/ijc n.47987

Wulandari, M., Siti Zulaekah, A., Soviana, E., \& Gz, S. (2016). Hubungan Antara Asupan Serat Dengan Kejadian Konstipasi Pada Pekerja Di PT. Tiga Serangkai Surakarta (Doctoral dissertation, Universitas Muhammadiyah Surakarta).

Tamura Akio, Tomita Toshihiko, Oshima Tadayuki, Toyosmia
Fumihiko, Yamasaki

Tahahisa, et al. (2016).

"Prevalence And Selef

Recognition of Chronic

Constipation : Result of Internet Survey." Journal Neurogastrointestinal motil. 677-84. 10. Indonesia.

Perkumpulan Gastroeterology. (2010). Konsensus Nasional Penatalaksanaan Konstipasi di Indonesia. Jakarta. 